Technical Note

\title{
The rate of repeating X-rays in the medical centers of Jenin District/Palestine and how to reduce patient exposure to radiation
}

\author{
Abed Al Nasser Assi ${ }^{1, a}$ \\ ${ }^{I}$ Medical-Imaging Department /Allied of medical science, Arab American University, Junín, Palestine \\ ${ }^{2}$ Medical Imaging Department/An-Najah National University \\ ${ }^{a}$ E-mail address: Abed.assi@aauj.edu
}

(received 31 August 2018; revised 1 November 2017; accepted 13 December 2017)

\begin{abstract}
Reduction of the patient's received radiation dose to as low as reasonably achievable (ALARA) is based on recommendations of radiation protection organizations such as the International Commission on Radiological Protection (ICRP) and the National Radiological Protection Board (NRPB). The aim of this study was to explore the frequency and characteristics of rejected / repeated radiographic films in governmental and private centers in Jenin city. The radiological centers were chosen based on their high volume of radiographic studies. The evaluation was carried out over a period of four months. The collected data were compiled at the end of each week and entered into a computer for analysis at the end of study. Overall 5000 films (images) were performed in four months, The average repeat rate of radiographic images was $10 \%$ (500 films). Repetition rate was the same for both thoracic and abdominal images (42\%). The main reason for repeating imaging was inadequate imaging quality $(58.2 \%)$ and poor film processing (38\%). Human error was the most likely reason necessitating the repetition of the radiographs (48\%). Infant and children groups comprised $85 \%$ of the patient population that required repetition of the radiographic studies. In conclusion, we have a higher repetition rate of imaging studies compared to the international standards (10\% vs. 4-6\%, respectively). This is especially noticeable in infants and children, and mainly attributed to human error in obtaining and processing images. This is an important issue that needs to be addressed on a national level due to the ill effects associated with excessive exposure to radiation especially in children, and to reduce cost of the care delivered.
\end{abstract}

Key words: patient dose; radiography; exposure; repeat rate.

\section{Introduction}

Medical imaging provides valuable information regarding the normal and abnormal anatomy that can occur within the human body. The main goal of radiography is to obtain the optimal diagnostic information by delivering the least radiation dose possible [1]. However, radiological studies should be performed in accordance with the general health of the individual patient without increasing harm by giving higher doses of radiation unnecessarily [2]. Diagnostic procedures result in more than $95 \%$ of the medical exposure to radiation worldwide [3-5]. There is no safe dose of radiation, as in theory, only a single photon or particle can cause damage of DNA which will potentially result in genetic alteration [6]. Being aware of the harmful effects of radiation, it is necessary to keep the total exposure level to radiation as low as possible. The International Commission on Radiological Protection (ICRP) recommends that medical exposure should be kept as low as reasonably achievable (ALARA) [7,13]. ALARA include; usage of high peak tube voltage $(\mathrm{kVp})$ and low milliampere second (mAs); use of high speed image receptor system, proper filtration, collimation to produce the smallest field size, optimum processing conditions and avoidance of repeated imaging. For this study, repeated film is defined as an x-ray film that is repeated for diagnostic purposes due to the inadequacy of the initial imaging study. Clearly, this will result in additional exposure to radiation by the patient [8]. Therefore, optimizing X-ray imaging in order to reduce the likelihood of repeated imaging and patient exposure to extra radiation is an important and complex process given the high standards required for obtaining a meaningful and informative $\mathrm{X}$-ray with a good quality to assist in the diagnostic process [9]. So, balance is needed between radiation dose and imaging quality without jeopardizing the imaging diagnostic accuracy [2].

The main aim of this study was to explore the rate of repeating $\mathrm{x}$-ray films in Jenin region and to provide a set of recommendations to reduce this repetition rate and to improve the radiation-exposure safety culture while providing the best care possible.

\section{Material and Methods}

In this study, all radiographic examinations were performed in radiological departments and centers in Jenin region both governmental and private (Al-Amal hospital, Al-Razi hospital, Dr. Khalil Soliman Hospital). Repeat analysis program (RAP) 
methodology was used [8]. The rejected films were those labeled as useless, or discarded radiographs. The literature was reviewed to generate a list of variables that are expected to result in radiographs repetition [6-12]. An analysis form was then populated in order to be filled by the radiographers if the film is deemed inadequate and needs repetition or if the film is rejected by the radiologist. The forms included the following information: type of examination, number of repeated films, reason for repetition, gender (female or male), and age group (< 5 years, 5-16 years and >16 years). The reasons for examination repetition were coded as one of the following: 1. Overexposure, 2. Underexposure, 3. Position error, 4. Patient movement, 5. Processing error, 6. Improper conditions of the film and/or darkroom. Following that, the parameters 1-2 were condensed into one variable that was called exposure error; factors 3-4 were collected into one variable called "human failure" (radiographer's mistakes).

\section{Subjects and statistical analysis}

Before the initiation of the study, the radiographers and the responsible radiologist were orally informed about the aims and forms of the study. A total of 28 radiographers (26 male and 2 female; the age mean was 23 years) with an experience time between 1-15 years (mean; 9 years) were recruited in the radiological centers and participated voluntarily in this study through performing the X-Ray images. Together with the radiologist, the radiographer has evaluated the quality of the image and both have decided whether to accept or reject the film. Their comments were then entered into the form. The total number of exposed radiographs and the repeated radiographs were determined over a four-month period. The collected data were compiled at the end of each week and entered into a computer for analysis by SPSS 17 software.

\section{Result}

In all radiological centers, 5000 patients were examined over a four month period. Five hundred patients $(10 \%)$ needed their image repeated (Table 1). The data analysis showed that the main reason for repeating or rejecting a radiograph image was due to human error (radiographer's mistake, parameter 3-4 ) which resulted in $48 \%$ of all repeated radiographs. The second reason for repeated films was due to exposure error, (1-2 parameter ) which represent $34 \%$ of repeated radiographs, The remaining radiographs $(18 \%)$ were repeated due to Processing film, Improper conditions of film and darkness inadequacy in the processing room. In comparison to the world's standards, we clearly have a high percentage of radiographer's failures and processing errors (Table 2).

The data analysis showed that $81 \%$ of the repeated or rejected images were performed in children under 5 years old and $15 \%$ in patients between 5-16 years old (Figure 1). In addition, the highest repetition rate was the same for both thoracic and abdominal images with a percentage of $42 \%$ while 16\% for skull (Figure 2).
Table 1. Table shows the distribution and the total number of the patient in a four month period time and the consecutively repeated examination.

\begin{tabular}{lcc}
\hline \hline Department & $\begin{array}{c}\text { Number of patient } \\
\text { in 4 months }\end{array}$ & $\begin{array}{c}\text { Number of } \\
\text { repeated films }\end{array}$ \\
\hline Jenin hospital & 3600 & 250 \\
Al-Amal hospital & 530 & 80 \\
Al-Razi hospital & 650 & 120 \\
Private radiology centers & 200 & 50 \\
\hline Total & $\mathbf{5 0 0 0}$ & $\mathbf{5 0 0}$ \\
\hline \hline
\end{tabular}

Table 2. Table shows the main reasons of repeated films which are very high in our study compared with international studies with the remark that human error was the main reason $(\mathbf{5 3 . 4 \% )}$ ) for repeated data $[15-16]$

\begin{tabular}{lcc}
\hline \hline Reason & Standard values & Study value \\
\hline Radiographer's error & $44 \%$ & $48 \%$ \\
Exposure error & $28 \%$ & $34 \%$ \\
Processing film, & $20 \%$ & $18 \%$ \\
Improper conditions of film and darkroom & & \\
\hline \hline
\end{tabular}

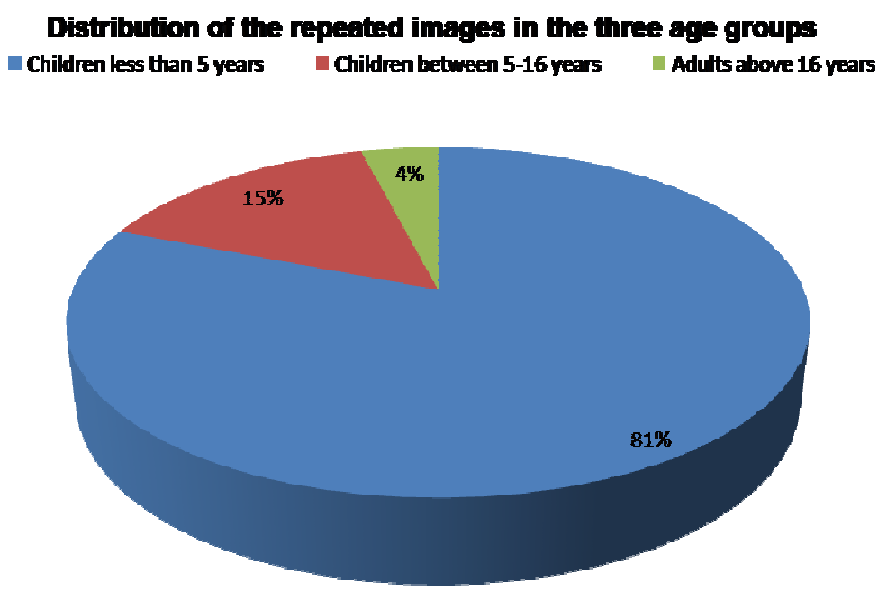

Figure 1. Figure shows the percentage of the repeated images in the three age groups.

\section{Distribution and repeat rats of the examined errans}

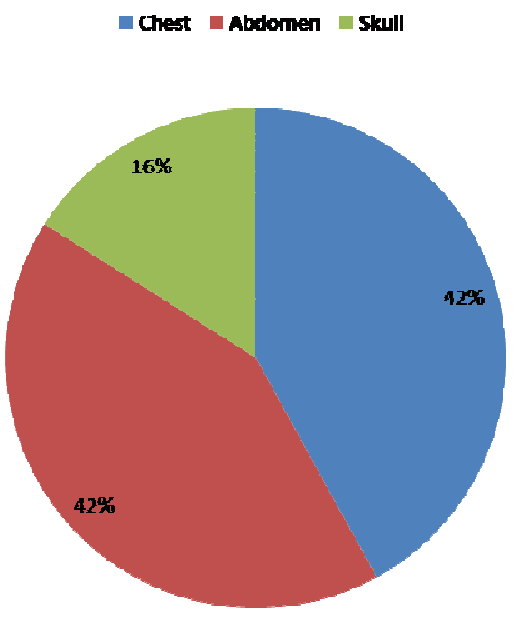

Figure 2. Figure shows the distribution and the percentage of the examined organs (thorax, abdomen and skull) and its repeat rate. 
Applying Chi-Square Test, there is a significant difference in the number of repeating radiographic films between the centers included in the study $(136.07$, df $=4 ; \mathrm{p}=0.00)$. Jenin Hospital has the lowest percentage of images repetition $(6.94 \%)$, AlRazi Hospital (15\%) and then Al-Amal Hospital (18\%). The private centers had a $25 \%$ rate.

\section{Discussion}

An analysis of radiographic imaging in the district of Jenin over a period of 4 months showed an average repeat rate of $\mathrm{x}$ rays of $10 \%$ which is significantly higher than the international repeat rate of $4-6 \%$ [13-15]. This indicates that some Palestinian patients are exposed to a higher ionizing radiation dose due to repeated imaging.

The data analysis showed that the main reason for repeating or rejecting a radiograph image was due to personal error (radiographer's mistake), this calls to attention the level of crews' performance in charge for producing radiographic image to identify the major problem they are facing during their working to get rid of the negatives found to reduce the amount of films repeating, and then work to raise their education and skills through the periodic presentations and workshops.

Past results have found that large hospitals cause less repeated radiographers than small hospitals. This is mostly because larger hospitals have higher volume of patients and daily radiographs that could lead to increased skills of the technicians in processing film.

Additionally, large centers and hospitals attract highly qualified professional staff which is likely to increase the skills of the technicians practicing in the associated imaging departments. It is advised that highly skilled staff in large hospitals should hold courses and workshops in other centers to sharpen and optimize the skills of their colleague technicians in smaller hospitals.

The high radiograph repetition rate leads to increased health care costs, since radiographers and radiologist valuable time is lost in analyzing inadequate radiographs and in repeating images. Additionally, this time wasted on inadequate graphs will likely result in increased length of stay in the hospital for patients who, otherwise, might be discharged earlier. This is a significant burden on multiple levels. Sick patients will be denied admission to the hospital due to high bed census due to delayed discharges, which also leads to higher costs for the patients and the Ministry of health.

The current work also demonstrated that the personal errors was the main factor for repeating radiographic examinations. Issues such as failure of collimation, beam angulations and patient centerings can be simply avoided through investing in better education and training of radiographers. Also, improvement of the radiographer's knowledge to use correct exposure parameters and correct radiographic position during the imaging process will potentially increase the image quality and decrease the rate of repeating films. So, additional costs through repeated films and use of chemicals and equipments are avoided. Furthermore, patient and staff time is saved [12].

\section{Conclusion and Recommendation}

There is a high rate of $\mathrm{x}$-ray repetition for same patients in Jenin, which mostly reflects the situation in other areas in Palestine. This is more noticeable in children who are more vulnerable to the hazardous effects of radiation that include cancer in addition to other diseases. Given that the human error in obtaining, handling and processing the x-ray images was the main reason to repeat imaging, a new educational and training program should be established to improve the radiographers' proficiency in these deficient areas. We propose that radiographers training to be tailored to obtaining images on difficult cases that need special attention and radiographic expertise. Additionally, improving communication between radiographers and patients to reduce body movement while obtaining radiographic images is of paramount importance. We hope these interventions will reduce the radiation dose delivered to patients and the costs of examinations.

\section{References}

[1] Bushberg JT, Seibert, JA, Leidholdt EM, Boone JM. The essential physics of medical imaging. Lippincott Williams and Wilkins, Philadelphia, 2002.

[2] Australian Radiation Protection and Nuclear Safety Agency. Radiation protection in diagnostic and interventional radiology. Radiation Protection Series Publication No. 14.1, Victoria, 2008.

[3] Supe SJ, Lyer PS, Sasane JB, et al. Estimation and significance of patient doses from diagnostic X-ray practices in India. Radiat Prot Dosimetry. 1992;43(1-4):209-211.

[4] Canon CL. McGraw-Hill Specialty board review radiology. McGraw-Hill Companies, New York, 2010.

[5] International Commission on Radiological Protection. Recommendations of the international commission on radiological protection. ICRP Publication 60, Oxford, 1991.

[6] Shabestani MA, Abdi R, Saber MA. Repeat analysis program in radiology departments in Mazandaran province - Iran; impact on population radiation dose. Iran J Radiat Res. 2007;5(1):37-40.

[7] Sniureviciute, M, Adliene D. Problems with film processing in medical X-ray imaging in Lithuania. Radiat Prot Dosimetry. 2005;114(1-3):260-263. 
[8] Al-Malki MA, Abulfaraj WH, Bhuiyan SI, Kinsara AA. A study on radiographic repeat rate data of several hospitals in Jeddah. Radiat Prot Dosimetry. 2003;103(4):323-330.

[9] Lau SL, Mak AS, Lam WT, et al. Reject analysis: A comparison of conventional filmescreen radiography and computed radiography with PACS. Radiography. 2004;10(3):183-187.

[10] Zewdeneh D, Teferi S, Admassie D. X-ray reject analysis in Tikur Anbessa and Bethzatha Hospitals. Ethiop J Health Dev. 2008;22(1):63-97.

[11] Committee on the Biological Effects of Ionizing Radiation. Health effects of exposure to low levels of ionizing radiation. BEIR V, Washington DC, 1990.

[12] McEntee MF, Kinsella C. An examination of practice during radiography of the clavicle. Radiography. 2010;16(2):125-130.

[13] International Commission on Radiological Protection. Recommendations of the international commission on radiological protection. ICRP Publication 103, Oxford, 2008.

[14] World Health Organization (WHO) 1980. Workshop on quality assurance in diagnostic radiology. Geneva, October 20-24.

[15] Papp JF, Quality Management in the Imaging Science (Fifth edition), Riverport Lane, Elsevier MOSBY( 2011).

[16] Ofori EK, Antwi WK, Arthur L, et al. Analysis and economic implications of X-ray film repeat/reject in selected hospitals in Ghana. West Afr J Radiol. 2013;20(1):14-18. 